\title{
An Interprofessional Approach to Teaching Advocacy Skills: Lessons from an Academic Medical-Legal Partnership
}

\author{
Vicki W. Girard \\ Georgetown University Law Center, vwg@law.georgetown.edu \\ Eileen S. Moore \\ Georgetown University Health Justice Alliance, moorees@georgetown.edu \\ Lisa P. Kessler \\ Georgetown University Health Justice Alliance, Ikp33@georgetown.edu \\ Deborah F. Perry \\ Georgetown University Center for Child and Human Development, dfp2@georgetown.edu \\ Yael Cannon \\ Georgetown University Law Center, yc708@georgetown.edu
}

This paper can be downloaded free of charge from:

https://scholarship.law.georgetown.edu/facpub/2329

https://ssrn.com/abstract=3740020

Journal of Legal Medicine, Vol. 40, Issue 2, Pp. 265-278.

This is an Accepted Manuscript of an article published by Taylor \& Francis in The Journal Of Legal

Medicine on Nov. 2, 2020, available online: http://www.tandfonline.com/10.1080/

01947648.2020 .1819485

This open-access article is brought to you by the Georgetown Law Library. Posted with permission of the author. Follow this and additional works at: https://scholarship.law.georgetown.edu/facpub

Part of the Health Law and Policy Commons, and the Legislation Commons 


\section{An Interprofessional Approach to Teaching Advocacy Skills: \\ Lessons from an Academic Medical-Legal Partnership}

Authors:

Vicki W. Girard ${ }^{1 *}$, Eileen Moore ${ }^{2}$, Lisa Kessler ${ }^{1}$, Deborah Perry $^{3}$, and Yael Cannon ${ }^{1}$

${ }^{1}$ Georgetown University Health Justice Alliance, Georgetown Law Center, Washington, D.C., USA

${ }^{2}$ Georgetown University School of Medicine, Washington, D.C., USA

${ }^{3}$ Center for Child and Human Development, Georgetown University Medical Center, Washington, D.C., USA

*Corresponding Author:

Vicki Girard, J.D.

vwg@georgetown.edu

ORC id: 0000-0001-9974-9705

Telephone 202-662-9900

Georgetown University Law Center

600 New Jersey Avenue, NW

McD Room 566

Washington, DC 20001 


\title{
An Interprofessional Approach to Teaching Advocacy Skills: \\ Lessons from an Academic Medical-Legal Partnership
}

\begin{abstract}
Medical students and educators recognize that preparing the next generation of health leaders to address seemingly intractable problems like health disparities should include advocacy training. Opportunities to acquire the knowledge and skills needed to effectively advocate at the policy level to promote systems, community, and population level solutions are a critical component of such training. But formal advocacy training programs that develop and measure such skills are scarce. Even less common are interprofessional advocacy training programs that include legal and policy experts to help medical students learn such skills.
\end{abstract}

This 2016-17 pilot study started with a legislative advocacy training program for preclinical medical students that was designed to prepare them to meet with Capitol Hill representatives about a health justice issue. The pilot assessed the impact of adding an interprofessional education (IPE) dimension to the program, which in this case involved engaging law faculty and students to help the medical students understand and navigate the federal legislative process and prepare for their meetings. Results from the pilot suggest that adding law and policy experts to advocacy-focused training programs can improve medical students' advocacy knowledge and skills and increase their professional identity as advocates.

Keywords: interprofessional education; advocacy; legislative process; health policy; professional identity 


\section{Introduction}

Traditionally, undergraduate medical education focuses on the professional competencies needed to treat patients safely and effectively. Acquiring the knowledge and skills to do so leaves little time to develop students' potential to serve as vehicles for change at the systems, policy, or public health levels. Over the past decade, however, the call to expand formal advocacy training during medical school has grown. ${ }^{1}$ (Earnest et. al. 2010) Some efforts to introduce the concept of physician as advocate early in medical training have shown a positive impact on medical students' embracing that aspect of professional identity. ${ }^{2}$ (Press, et. al. 2015) Including advocacy training in medical students' curriculum has also shown promising results in developing their confidence in themselves as effective advocates. ${ }^{3}$ (Belkowitz et. al., 2014) More advocacy training is needed, however, if we want medical professionals to routinely see themselves as agents of change who can help address questions related to access, disparities, costs, and other of society's major healthcare problems. ${ }^{4}$ (Croft, et. al., 2012)

In addition to adding advocacy training across all levels of medical education, teaching students to collaborate across professions is also a priority for many schools. ${ }^{5}$ (Dow \& Thibault 2017; Pettignano et.al 2014) Recognizing that more than half ${ }^{6}$ (Graham \& Bernot 2017) and perhaps even up to $80 \%{ }^{7}$ (Magnan 2017; Hood 2016) of a patient's health is attributable to factors other than healthcare, educators strive to produce medical providers who know how to collaborate with other professionals to address social determinants of health. ${ }^{8}$ (Dow \& Thibault 2017) On a broader scale, such education and training efforts acknowledge that interprofessional teams are better able to advocate for systems, legislative, and policy changes for patients and communities. 
${ }^{9}$ (Hubinette, et. al, 2016) Another key benefit of an interprofessional approach to advocacy is that it may make advocacy less overwhelming for individual physicians. Doctors who experience the benefits of joining with other stakeholders who bring different knowledge and expertise to advocacy efforts may be less intimidated about assuming an active role and adding their medical expertise to a collective approach to solving complex health policy problems. ${ }^{10}$ (Hubinette et. al., 2016)

Including law and policy experts in advocacy training programs for medical students suggests a natural way to enhance the robustness of such programs while also offering students an innovative interprofessional educational (IPE) experience. Conversations about such programs, however, rarely consider or directly address how lawyers could contribute to such training. ${ }^{11}$ (Congdon 2016) Nor do medical educators (other than in the specific context of medical-legal partnerships) seem to think about how to include lawyers in other interprofessional training efforts. In this report on our pilot study, we describe our efforts to harness the potential IPE synergy of adding the expertise of law faculty and students to an advocacy training program for pre-clinical medical students in the context of a federal legislative "Capitol Hill Advocacy Day." We also report our results of the impact this IPE approach had on medical students' learning, skills, confidence, and interest in and around engaging in future advocacy.

\section{Materials and Methods}

\section{Building on an existing advocacy training program for medical students}


The Health Justice Alliance is an academic medical-legal-partnership (MLP) between Georgetown University Medical and Law Centers that brings together healthcare professionals and lawyers to address social determinants of health that require a legal solution. ${ }^{12}$ (Regenstein, et. al. 2018) The MLP model not only encourages, but depends upon a robust and expansive view of interprofessional collaboration and practice and the inclusion of legal professionals in IPE efforts. ${ }^{13}$ (Theiss, et. al., 2019) At Georgetown University, the School of Medicine, School of Nursing and Health Studies, and the Law Center, all contribute faculty, staff, and students to the MLP efforts of the Health Justice Alliance. Thus, in addition to direct legal and health services for children and families, the Health Justice Alliance also supports a constellation of interprofessional education activities.

One of these activities, is Georgetown University School of Medicine's Capitol Hill Advocacy Day Program (the Program), which has been providing preclinical medical students on its Health Justice Scholars (HJS) Track a legislative advocacy experience at the federal level for the past ten years. The HJS Track, started in 2009, is a four-year longitudinal academic track that empowers student physicians to become advocates for the underserved. Each year $15-20 \%$ of the approximately 200 incoming new medical students class are accepted onto the HJS Track based on an application submitted during the middle of their first year, which includes a statement of interest reviewed by the HJS faculty director. Students who are accepted onto the HJS Track are required to participate in specific activities each year of medical school. In their second year of medical school, the required HJS activity is the Program, which was the focus of this pilot study. Traditionally, the School of Medicine had sole responsibility for managing the Program. In 2016, 
when the Health Justice Alliance was established, we had the opportunity to integrate law faculty with legislative and advocacy experience and law students participating in a law school seminar on MLP, into the Program. Our interest in doing so was to assess the feasibility of integrating law students and faculty into the existing Program to create an IPE experience. Included in the measures we wanted to assess were how adding legal expertise would impact medical students' self-reported (1) understanding of the legislative process and pending bills selected for advocacy; (2) preparation for a congressional representative meeting; (3) confidence and capacity around legislative advocacy generally; and (4) interest in participating in future advocacy efforts as part of embracing a broader view of professional identity.

\section{Adding legal experts to the Program}

In the Program as originally conceived and implemented, medical students work in small groups to identify a Congressional bill with a "health justice" focus (i.e., one advancing health care for vulnerable or underserved patients); craft a message of support; and then meet with one or more Congressional representatives to discuss their position on the legislation. During Fall 2016, this traditional version of the Program was provided to 38 medical students. The Program requirements included physical attendance at a minimum of 3 of 4 one-hour lunch-time lectures: (1) Choosing a People to Serve; (2) Media and Communications; (3) Advocating on the Hill; and

(4) Making Your Voice Heard. Students were allowed to miss one lecture as a way to account for conflicts with required medical school curricula, which were imposed on different cohorts of students at different times. All sessions, however, were recorded so that students had access to the same content. In order to account for differences between the experience of attending the 
sessions in-person and watching the recordings (including the possibility that some of the medical students may not have taken the time to view the recordings) faculty were mindful to repeat key substantive points related to Capitol Hill advocacy during the third and fourth lectures. Overall, however, this pilot study did not directly account for the possibility that student survey responses may have been impacted by missing either of the last two lectures.

Following completion of the fall lecture series, in January 2017, the research and evaluation team worked with the HJS Track administrative assistant to divide the 38 students on the HJS Track into two distinct groups. Using a random number table, the 38 medical students were assigned to either a "Control Group" (17 students who continued in the traditional Program) and an "InterProfessional Education (IPE) Group" (21 students who collaborated with law faculty and students throughout the remainder of the Program).

The Control Group's continuation in the traditional Program started with a lecture in midJanuary from a third year medical student, overseen by medical faculty, on how to find a bill using www.congress.gov. Students also received guidance during that lecture on how to schedule appointments with U.S. senators and representatives. At the end of the session, students selfselected into teams of 2-5 based on interest areas with a health justice focus and worked over the next two months to prepare for Capitol Hill Day. Each team selected a pending bill based on interest and whatever research they felt comfortable doing to identify pending legislation. Teams also were responsible for scheduling 1-3 meetings with representatives, and working together to 
plan their pitch and presentation (relying on whatever experiences, research, and resources members brought to the process). During that time, the HJS Track medical faculty director met with teams and answered questions as requested, and the HJS Track administrative assistant kept records on selected bill topics and scheduled meetings. One of the hypotheses of the pilot study was that adding legal expertise to the bill selection process would improve the experience for medical students so no assistance with selection of bills was provided to the Control Group.

The IPE Group followed a model where preparation for Capitol Hill Day included dedicated time working with law students and faculty. Law students who participated in the Program were second and third-year students enrolled in a formal seminar on medical-legal partnership at the Law Center. Providing support for their assigned medical student teams in the Program accounted for $20 \%$ of students' grades and included two in-person joint classes at the medical school and several other virtual team meetings and communications. Law faculty worked with medical faculty to frame the guidelines for the law students' support and used some of the time during the first few weeks of the law seminar to prepare the law students to meet and guide the medical student teams through their role in the Program. Of the ten law students enrolled in the MLP seminar, at least half had some level of former legislative experience (either direct work experience on Capitol Hill or prior positions that provided them with some familiarity with the federal legislative process). Also during that time, rather than leaving bill selection up to the medical students (as was allowed for the Control Group), law and medical faculty worked together to identify areas of interest on a variety of health justice related issues based on historical experience of medical faculty about commonly selected topic areas. Using these broad 
topic areas as a starting point, law faculty and librarians researched pending legislation and identified six bills that were considered a good fit for the Program ("good fit" was based on factors related to complexity, status, potential for positive impact, and direct connection to students' health justice interests).

Law students in the MLP seminar were then divided into teams of 1 or 2 and assigned specific bills for which they were designated "consultants." (Note: for teams with 2 law students, faculty purposely paired students without federal legislative experience with students who did. Faculty also solicited input from the law students about their preferred areas of interest.) The law students were then tasked with preparing short summaries of their assigned bills for the medical students. Before the first joint medical and law student class in February, medical students in the IPE Group received a virtual binder of bill summaries and submitted their top 3 choices for their advocacy efforts. Based on expressed preferences, teams of 3-4 medical students and 1-2 law students were created for each bill. The medical students were then assigned to read two short papers on developing effective talking points, while law students received more specific instructions during their law seminar time on how to guide medical students in developing talking points, how to facilitate research on the legal/policy side of the issues, how to evaluate the accuracy of legal content, and how to explain the use of structure and rhetorical devices to improve persuasiveness. 
Once the groundwork described above was completed, law and medical faculty worked together to prepare and deliver two, hour-long, joint IPE classes. The first class started with a short lecture by law faculty on the federal legislative process focused on how a bill becomes a law and the steps along the law-making path. The purpose of that lecture was to assure a common baseline of knowledge among the medical students for understanding and evaluating the legislative status of bills and how that might impact an advocacy strategy and to refresh law students' understanding of the process (which is part of the law school curriculum for all firstyear law students). Following that lecture, students broke into their assigned bill teams. The teams then spent the rest of their class time jointly reviewing the content and structure of their bills with the law and medical students brainstorming potential areas for research and specific advocacy points they thought should be made. Based on discussions during their MLP seminar, the law students were able to guide the medical students through the process of understanding the substance and status of their selected bills; throughout their discussions, team members shared ideas for researching the political, financial, health, and social justice arguments and framing talking points. During this class time law and medical faculty rotated among the groups to answer questions and lend expertise on legal and medical issues raised by students. At the end of class, medical students were assigned primary responsibility for drafting talking points and each was told to bring 2-3 to the next joint class. Since the Program's focus was on preparing medical students to advocate on Capitol Hill, we did not emphasize the formal transmission of medical information or experience to the law students, although law students were instructed to encourage their medical teams to use their healthcare related knowledge and personal stories where relevant to guide their research and enhance their talking points. At the end of this session, the students made plans for collaborating over the next few weeks (by zoom, e-mail, etc.) and 
divided responsibility for scheduling appointments with legislative representatives (based on student voter registration information).

During the second IPE session, the teams reviewed and discussed the medical students' talking points and refined their presentations. Law students contributed legal background relevant to the presentation and developed potential questions and counterarguments to help prepare the medical students for meetings. One team created a "one-pager" to leave behind, which we adapted into a template for use by the other teams. Following this last formal joint IPE session, teams continued to coordinate appointment efforts through the beginning of March. A 1-month interruption occurred between the final joint session and Capitol Hill Day due to exams and spring break. Teams navigated that time with varying approaches; while we did not impose any specific requirements on teams, some of the groups remained in contact and continued to work together. On the actual day of the Capitol Hill visits, 2 of the 6 teams had a law student join them for at least one of their scheduled meetings.

\section{Survey content and administration}

Following the Capitol Hill Day event in March, an online post-intervention survey was used to assess the impact of the Program on both groups of medical students. Our goal was to see if offering advocacy training to medical students using an IPE approach that integrated legal experts had any impact on students' understanding of the legislative process and their confidence or interest in acting as health justice advocates. The survey included nine short questions with 
Likert responses and six open ended questions. Prior assessments of educational experiences have led us to adopt a retrospective post-test as students often inflate their knowledge of topics under study. Only after exposure to the new context are they able to accurately assess the change in knowledge that resulted from this educational experience. Finally, as part of our quality assurance and evaluation efforts, feedback sessions with each group were scheduled with the law and medical faculty team; additional qualitative data were gathered during these sessions by a research assistant.

\section{Data analysis}

Quantitative data were summarized based on post-intervention responses collected from $76 \%$ and $95 \%$ of the Control and IPE groups, respectively; resulting in sample sizes of 13 and 20. Percent differences in favorable responses between the groups were assessed. Mean scores were calculated and statistically significant differences were assessed using a one-way analysis of variance (See Table 1). Percentages are reported in the narrative based upon the proportion of students endorsing different response categories in addition to mean differences for ease of interpretation. Open-ended responses were analyzed using qualitative data approaches consistent with a grounded theory approach. This methodology balances the discipline of systematic coding with the flexibility of exploring and considering themes as they emerge. ${ }^{14}$ (Strauss \& Corbin1994) Themes were identified and exemplary quotations were selected to represent those emerging themes. 


\section{Results}

The survey was administered to both groups of medical students and 87\% (33) responded. Inferential statistics were calculated to compare responses from the two groups. Georgetown University's Institutional Review Board for Social and Behavioral Sciences Committee determined that the pilot study was not human research (Study ID 00001301).

Four of the nine questions revealed statistically significant differences in the mean scores of students in the IPE versus Control Groups: compared to the members of the Control Group, individuals from the IPE Group reported spending more time preparing ( $\mathrm{p}<.03)$, and being better prepared to discuss their bills with a legislator or a staffer. One-third of the Control Group reported they spent less than 2 hours preparing, while $90 \%$ of the IPE Group spent 2 or more hours preparing; almost half of those reported spending 4 hours or more. Many also felt that the training had better prepared them to tailor a message to support their advocacy efforts. Consistent with our goals for an expanded sense of professional identity, members of the IPE Group also were significantly more likely to report being interested in pursuing future opportunities in advocacy.

Table 1. Mean Differences in Responses from Medical Students in the IPE $(n=20)$ versus Traditional Program (n=13)

\begin{tabular}{|l|l|l|l|}
\hline Construct/Skill & Question & Means & F-statistic \\
& & & p-value \\
\hline
\end{tabular}




\begin{tabular}{|c|c|c|c|}
\hline $\begin{array}{l}\text { Preparation Time } \\
(1=\text { less than } 1 \\
\text { hour; } 2=1-2 \text { hours; } \\
3=2-4 \text { hours; and } \\
4=4 \text { or more } \\
\text { hours })\end{array}$ & $\begin{array}{l}\text { About how much time did you } \\
\text { spend preparing for your } \\
\text { presentation on Hill Advocacy } \\
\text { Day? }\end{array}$ & $\begin{array}{l}\text { IPE: } 3.35 \\
\text { Control: } 2.77\end{array}$ & $\begin{array}{l}\mathrm{F}=4.887 \\
0.0346 *\end{array}$ \\
\hline $\begin{array}{l}\text { Preparedness } \\
(1=\text { not at all, } 2=a \\
\text { little, } 3=a \text { lot })\end{array}$ & $\begin{array}{l}\text { How prepared did you feel to } \\
\text { discuss your bill with a } \\
\text { legislator or staffer? }\end{array}$ & $\begin{array}{l}\text { IPE: } 2.9 \\
\text { Control.: } 2.61\end{array}$ & $\begin{array}{l}\mathrm{F}=4.057 \\
0.05 *\end{array}$ \\
\hline $\begin{array}{l}\text { Tailor a message } \\
\text { (not well at all=1; } \\
\text { slightly well=2; } \\
\text { moderately } \\
\text { well=3; } \\
\text { very well=4) }\end{array}$ & $\begin{array}{l}\text { How well did this program } \\
\text { prepare you to tailor a message } \\
\text { to a particular audience to } \\
\text { persuade that audience? }\end{array}$ & $\begin{array}{l}\text { IPE: } 3.15 \\
\text { Control: } 2.69\end{array}$ & $\begin{array}{l}\mathrm{F}=3.34 \\
0.07^{+}\end{array}$ \\
\hline $\begin{array}{l}\text { Likelihood to } \\
\text { pursue advocacy } \\
\text { (not at all likely=1; } \\
\text { somewhat } \\
\text { unlikely=2; } \\
\text { somewhat } \\
\text { likely=3; } \\
\text { extremely } \\
\text { unlikely=4) }\end{array}$ & $\begin{array}{l}\text { How likely are you to pursue } \\
\text { future opportunities to } \\
\text { advocate for health-related } \\
\text { legislation? }\end{array}$ & $\begin{array}{l}\text { IPE: } 3.85 \\
\text { Control.: } 3.46\end{array}$ & $\begin{array}{l}\mathrm{F}=4.737 \\
0.04 *\end{array}$ \\
\hline
\end{tabular}

Key: $*=$ Significant at $\alpha \leq 0.05,{ }^{+}=$Marginally Significant at $\alpha \leq 0.1$ 
Nearly all of the students in the IPE Group reported being more prepared to discuss their bills with a legislator or a staffer $(90 \%$ versus $62 \%$ rating their level of preparedness in the highest category). Four times as many medical students who worked with the law students reported feeling "very well prepared" to tailor a message to support their advocacy efforts $(35 \%$ versus $8 \%$ ). The majority of the members of the IPE Group reported being "extremely likely" to pursue future advocacy opportunities (85\% versus $54 \%$ in the Control group).

Qualitative analysis of the open-ended survey questions, combined with post-intervention feedback sessions with the Control and IPE Groups were consistent with the statistical results. According to the IPE Group, law faculty and students assisted them on everything from minute details related to their one-pagers, such as using footnotes rather than in-text citations, to larger rhetorical strategies, such as anchoring their talking points within a personal story. Members of some teams shared their impression that law students with prior Hill experience were particularly adept at helping them conceptualize a Hill visit and prepare successfully. While the majority of medical students in the IPE Group appreciated having legal experts help them read their bills and prepare one-pagers and talking points, one finding emerged that helped the team plan for future cohorts: in the IPE group, some medical students noted that law students without Hill experience were not as helpful or engaged as those with Hill experience.

Another significant finding that emerged from the qualitative data was related to the timing of the IPE work sessions. Teams in the IPE Group that communicated with their law students 
within two days of the actual Hill Advocacy Day identified that opportunity as "an incredibly important part of their success," in part because they said it helped them fill the gap between the formal preparation sessions and their actual meeting dates on the Hill. These informal communications were arranged between the students in each team and were not required by faculty overseeing the program, but the comments helped clarify that the IPE experience of having law students available to consult with them played an important role in reinforcing the medical students' sense of readiness to discuss their issues and articulate policy perspectives. It also suggests that the benefits of IPE may require some longitudinal or reiterative programming if we seek to have a more substantial and lasting impact on medical students' advocacy training moving forward. Finally, the medical faculty member in the Program reported that in her discussions with medical students throughout the spring (both during formal sessions with the IPE teams and in informal meetings in her office with members of the control and IPE groups), medical students in the IPE Group tended to be more accurate in their descriptions of where bills sat in the lawmaking process (under review in the House, passed in the Senate, etc.), how many times the bills had previously been introduced, and how the proposed legislation fit into the current political climate. Overall, the IPE Group's access to legal expertise appeared to enhance their understanding of the subject matter of their bill and the political process.

Regarding their Capitol Hill Advocacy Day experience, during the informal debriefing sessions that were held with law and medical faculty after the event, the medical students in the Control Group expressed a desire for help reading and understanding their selected bills, writing a onepager, developing talking points, and practicing their presentations. Many felt they went into 
discussions with legislators without knowing what to expect. They also said a refresher on how a bill becomes law and perhaps a guide to writing about the law would have been helpful. Some of these comments may have resulted from a diffusion of knowledge about the respective experiences of the Control and IPE groups.

\section{Discussion}

As reflected in the quantitative and qualitative results, the addition of law faculty and students generally resulted in a more positive IPE experience for medical students and enriched the learning and advocacy outcomes and goals of the Program. The combined quantitative and qualitative results of this pilot study, as well as the impressions of law and medical faculty who have maintained contact with HJS Track students who participated in this study, revealed a genuine excitement and willingness on the part of second-year medical students to acquire advocacy expertise and relevant new skills. For medical schools where the prospect of bringing students to Washington, D.C. is not practical, the Program in this pilot study could easily transfer to advocacy opportunities with state and local governments. For example, interested medical schools could begin by tracking state and local health-related legislative efforts and identifying opportunities for participation in the process. In Washington, D.C., for example, the City Council allows students who are residents to participate in the legislative process through written and oral testimony. Recently, the Health Justice Alliance Law Clinic supported a team of law and medical students who testified before that body on the issue of lead in public housing. 
Other MLPs also report success in more local advocacy efforts. Yale School of Medicine's Healthy Lives Program for pediatric medical residents is one example of an advocacy training program that focuses more specifically on local health policy efforts. Similarly, the Health Law Partnership in Atlanta, Georgia has also reported on the success of its MLP's local legislative efforts as has the Health Justice Project at Loyola University Chicago. While the academic MLP model offers some unique advantages (teaching expertise, ability to mandate participation, etc.), the option of seeking out members of the local legal community and other public health policy experts who are engaged in advocacy and willing to partner in this type of IPE endeavor also exists and may be embraced by legal advocates as an exciting new way to work with students.

In terms of improving the IPE experience of this Program, the IPE and Control Groups both expressed a strong desire for access to "content experts" (i.e., individuals with particular health advocacy expertise or with deeper knowledge of healthcare finance and reform). Drawing on available community partners and experts could be one way to fill this gap in the IPE experience and deepen the access to legal and policy expertise beyond that provided by law school faculty and students. In terms of "medical experts," the IPE and Control Groups also discussed the potential benefit of having fourth-year medical students on their teams. Adding that clinical experience to their teams was suggested as a way to provide credible anecdotes about a particular health justice issue and more effectively leverage their expertise as health advocates with lawmakers. 
Our preliminary assessment of the Program's impact was limited by the small sample size and differential response rates across the two groups. Another limitation was that medical students in the pilot study had voluntarily enrolled in an educational track focused on health justice; their interest in future advocacy may have been high to start, resulting in diminished differences between the Control and IPE Groups. Plans to enroll students in a longitudinal study to assess the longer-term impact of interprofessional advocacy training on medical students' professional development and career choices in the context of this Program and other MLP activities at Georgetown University are underway. Among the challenges of increasing the number of medical students that can be included in the IPE experience is the limited number of law and medical faculty available to lead the necessary programming and the need for additional law students to support the type of collaborative teamwork described in this pilot study. One way to build capacity that we have explored is recruiting law students as pro bono volunteers to work with the medical student teams rather than depending on a small number of seminar students. That approach supports increase the number of medical students who have the IPE experience, but it also introduces scheduling and other challenges that reduce the level of faculty guidance and engagement needed to best meet the IPE goals. In whatever manner integrating legal expertise into advocacy training can be accomplished, however, the results of this pilot study underscore the potential value of an IPE experience in that context.

Overall, we are encouraged by the results of this pilot study, which suggest that adding legal expertise to advocacy training can provide concrete benefits to medical students' ability to advocate effectively on health issues. We hope our results encourage other medical schools to 
find ways to engage in more deliberate advocacy training and that it may inspire other academic health centers to consider the benefits the MLP model of healthcare delivery can bring to educational settings. Providing medical students a more sophisticated understanding of the legislative process and facilitating opportunities for them to put advocacy training into practice may help build students' confidence in their own advocacy abilities and improve the likelihood that they will engage in such efforts in the future. Additional studies can build on this pilot to assess more rigorously whether adding an IPE dimension to advocacy training programs achieves these and other goals.

Finally, although this study was limited to measuring the impact on medical students of advocacy training that included law students and faculty, we hope that we and others will expand on our work and continue to strive for a much broader view of IPE that includes other categories of professionals and providers of health and legal services. Such a stance is consistent with the MLP movement generally, which is founded on the premise that an effective multi-disciplinary approach to health must embrace not only lawyers, doctors, nurses and other allied health professionals, but also public health, policy, business, finance, and other experts. Indeed, maximizing the types of professionals who are part of the MLP movement is necessary to achieve the model's national goals of improving outcomes at the patient, system, and population levels.

\section{$\underline{\text { Acknowledgements }}$}


The authors extend their thanks to AAA and BBB for their survey and other research help in connection with this pilot study.

\section{$\underline{\text { Declaration of Interest Statement }}$}

None exist

$\underline{\text { References }}$

1. See Mark Earnest et. al., Perspective: Physician Advocacy: What Is It and How Do We Do It?, 85 ACAD. MED. 63 (2010).

2. Valerie Press, et. al., First-year Medical Student Attitudes About Advocacy in Medicine Across Multiple Fields of Discipline: Analysis of Reflective Essays, 2 J. RACIAL \& ETHNIC HEALTH DISPARITIES 556, 561-63 (2015).

3. Julia Belkowitz et. al., Teaching Health Advocacy to Medical Students: A Comparison Study, 20 J. PUB. HEALTH. MGMT. \& PRACTICE E10, E17-18 (2014).

4. Daniel Croft, et. al., Perspective: Is it time for Advocacy Training in Medical Education?, 87 ACAD. MED. 1165, 1167 (2012).

5. Alan Dow and George Thibault, Interprofessional Education - A Foundation for a New Approach to Health Care, 377 NEW ENGL. J. MED., 803, 804-05 (2017); see also Robert Pettignano, et. al., The Health Law Partnership: A Medical-Legal Partnership Strategically Designed to Provide a Coordinated Approach to Public Health Legal Services, Education, Advocacy, Evaluation, Research, and Scholarship, 34 J. OF LEGAL MED. No. 1 (2014). 
6. Garth Graham and John Bernot, An Evidence-Based Path Forward To Advance Social Determinants Of Health Data, HEALTH AFFAIRS BLOG, October 25, 2017.

7. Sanne Magnan, Social Determinants of Health 101 for Health Care: Five Plus Five, NATIONAL ACADEMY MED. PERSPECTIVES, Discussion Paper (2017); C. Hood, et. al., County Health Rankings: Relationships Between Determinant Factors and Health Outcomes, 50 AMER. J. PREVENTIVE MED. 129 (2016).

8. See Alan Dow and George Thibault, supra note 5, at 804.

9. See Maria Hubinette et al., Lessons From Rocket Science: Reframing the Concept of Physician Health Advocate, 91 ACAD. MED. 1344, (2016).

10. Id. at 1345 .

11. See, e.g., Heather Congdon, Interprofessional Education (IPE) Practices at Universities Across the United States with an Established IPE Infrastructure in Place, $5 \mathrm{~J}$.

INTERPROF'L EDUC. \& PRACTICE 53 (2016).

12. E.g., Marsha Regenstein, et. al., Addressing Social Determinants of Health Through Medical-Legal Partnerships, 37 HEALTH AFFAIRS 380 (2018).

13. J. Theiss, et. al., A System-Level Approach to Addressing Health-Harming Legal and Social Needs: A Case Study of the NYC Health + Hospitals and Legal Health MedicalLegal Partnership, available at https://medical-legalpartnership.org/mlp-resources/nychealth-and-hospitals/ accessed April 11, 2019.

14. Anselm Strauss \& Juliet Corbin, Grounded Theory Methodology in Handbook of Qualitative Research 273-85 (N. L. Denzin \& Y.S. Lincoln eds., 1994). 